\title{
Restricted entitlements for skilled temporary migrants: the limits
}

\section{of migrant consent}

Forthcoming (2017) as: Martina Boese and Kate Macdonald, "Restricted entitlements for skilled temporary migrants: the limits of migrant consent", Journal of Ethnic and Migration Studies, 43:9, pp.1472-1489

\begin{abstract}
Temporary labour migration programs have often attracted significant controversy, particularly with regard to provisions that restrict the social entitlements available to temporary migrant workers, compared with other categories of residents. Advocates of such restrictions have argued that migrants freely choose to participate in temporary migration schemes on the prevailing terms, and are free to leave at any time if such participation no longer serves their interests. Our central goal in this paper is to critically evaluate such consent-based justifications for restricted social entitlements of temporary migrant workers, with reference to empirical evidence concerning the practical social and economic conditions of choice experienced by these temporary migrants. Drawing on evidence from one major receiving country-Australia - we show that consent based justifications for restricted social entitlements fail to fully account for either the practical complexity of individual migration choices, or the de facto operation of Australia's skilled temporary migration program as a 'test run' for potential future permanent residents or citizens. By bringing sociological analysis of lived migrant experiences into critical engagement with normative debates about restricted social entitlements, we contribute to the bridging of empirical and normative migration debates, which too often evolve in parallel.
\end{abstract}

\section{Keywords}

Temporary labour migration, migrant workers, social entitlements, consent, Australian skilled migration policy 


\section{Introduction}

Temporary labour migration programs - regulating the migration of foreign workers who are granted permission to live and work in a receiving country for a fixed period of time-have grown in importance even in traditional settler countries like Australia and Canada, and have often attracted significant controversy. Critics of these programs have highlighted concerns about the negative impacts of temporary migrant intakes on employment opportunities and working conditions for local workers, exploitation of vulnerable categories of migrant workers (Lenard and Straehle 2010; Stilz 2010), and the erosion of democratic values and social cohesion through the creation of a category of 'second class' citizens (Walzer 1983; Wellman 2009). Particular debate has focused on restricted social entitlements of temporary migrant workers, compared with other categories of residents. In contrast, architects and supporters of such programs have often celebrated what they view as potential 'win-win-win' outcomes: for sending countries in the form of remittances, for receiving countries in the form of willing and sometimes highly skilled workers, and for labour migrants themselves in the form of gains from work that is usually higher paid than available employment in sending countries (Agunias and Newland 2007; GCIM 2005).

An important argument invoked in analyses of such restrictions on the social entitlements of temporary migrant workers has centred on the consent of migrant workers, reflected in their voluntary individual choices to migrate under the terms of the prevailing regime (Ottonelli and Torresi 2012). On this view, migrants make informed choices to voluntarily trade-off certain categories of social entitlements in order to access both short-term gains in incomerelative to earnings available in departure countries - and longer-term opportunities to advance personal life-projects. Moreover, it has been argued that restricted entitlements for individual temporary migrants can facilitate admission of greater numbers of migrants overall, summarized in the notion of a 'trade off' between rights and numbers, thus satisfying the mobility aspirations of a larger number of people (Ruhs 2013; Martin and Ruhs 2008).

Our central goal in this paper is to critically evaluate the grounds on which the fairness of restricted social entitlements for temporary migrant workers is defended through consentbased arguments of this kind. As we explain further below, our analysis focuses on a skilled temporary migrant worker program operating in one specific country-Australia. The program, referred to as the subclass 457 visa program, aims to attract skilled workers to work for an eligible employer sponsor in a selected skilled occupation for a limited period.

A focus on one program in a single country enables us to analyse the way in which relevant restrictions of entitlements are justified by many of the program's architects and advocates. Consent-based arguments in defence of such restrictions are shown to be centrally grounded in a commitment to the liberal values of individual autonomy and welfare, and to a view that ensuring consent of affected individuals provides a strong basis for protecting these values. According to such arguments, the constrained social entitlements available to temporary migrants under the 457 visa program can be justified on the grounds that migrants have freely chosen to participate in the temporary migration scheme on the existing terms and are free to leave at any time if such participation no longer serves their own interests, as has been argued in relation to temporary migration programs in other countries (see for example Pritchett 2006). To be clear, we are not suggesting that such arguments underpin the central rationale for the program's existence; rather that such arguments are used to justify the fairness of the restricted social entitlements of temporary skilled migrants. 
As we explain further below, this justification embodies a number of assumptions about how migrant workers make choices about migration, and the corresponding capacity of individual consent to secure the autonomy and welfare of migrant workers. We evaluate these assumptions with reference to empirical evidence concerning the practical social and economic conditions of choice experienced by temporary skilled migrant workers in Australia. This enables us to bring sociological analysis of lived migrant experiences into critical engagement with normative debates about the role of voluntary migrant choices in justifying policies of restricted entitlements - taking some preliminary steps towards bridging empirical and normative migration debates, which too often evolve in parallel.

To conduct this assessment, we draw on empirical research from in-depth interviews conducted with one professional group of workers under the 457 visa program-overseas qualified nurses working in the Australian hospital sector. This research was carried out during 2012 and 2013, and involved analysis of policy and legal documents, interviews with 26 migrant workers who have worked as registered nurses in Australia while holding a 457 visa, ${ }^{1}$ and interviews with 21 other key informants, including participants from government working in professional roles in implementing the visa regime, employers, and trade unions. ${ }^{2}$ The interviews were recorded, transcribed and analysed with the assistance of qualitative data analysis software.

As a migrant group, registered hospital nurses working in Australia are relatively privileged in the sense that they are highly trained professionals, whose skills are in demand internationally. Moreover, working conditions in the Australian hospital nursing sector are protected through a range of labour market regulations, high levels of unionization and regularised work arrangements. Although the experiences of workers in one particular sector or country cannot be assumed to represent those in differing circumstances, this particular subgroup of temporary migrant workers nonetheless offers a useful case for scrutinising the consent-based rationale of temporary migration visa programs. If even workers in this relatively privileged group of temporary migrants are unable to make voluntary choices in the ways assumed by consent-based justifications of restricted social entitlements, then this raises significant questions about the validity of such justifications in other sectors of the economy and other countries, in which the capacities of workers are relatively more constrained.

We present evidence suggesting that key assumptions underpinning this consent-based justification for restricted social entitlements are not supported by empirical research on the lived experiences of temporary migrant nurses in Australia. Although most migrant nurses' choices to participate in the temporary migration scheme are 'free' in the sense of lacking direct coercion, in making such choices many nurses lack relevant information regarding the consequences of the visa scheme's provisions for their individual migration experiences. Moreover, their capacity to withdraw from the scheme if such participation no longer serves their interests is often practically constrained in significant ways. Finally, we argue that these constraints experienced by nurses are not accidental blind spots, but are directly produced by the design of the program as a potential pathway to permanent residency. Consent-based justifications for restricted social entitlements can therefore be understood as wrongly

\footnotetext{
${ }^{1}$ Table 1 in the Appendix provides a more detailed overview of the participants' gender and nationalities.

${ }^{2}$ Key informant interviews included representatives from the former Department of Immigration and Citizenship (DIAC) and the Fair Work Ombudsman (FWO); officials from the Australian Nursing Federation (ANF) and the Australian Council of Trade Unions (ACTU); an official from an employer association (ACCI); representatives of a recruitment firm; nurse unit managers; and human resource management personnel.
} 
holding vulnerable individual workers responsible for the consequences of their choices, without empowering them to make informed and autonomous choices of normatively defensible kinds.

\section{The 457 visa program}

The 457 visa program is the major program in Australia that is designed to facilitate skilled temporary migrant work. The program was officially adopted under a centre-right Coalition government in March 1996. It is an uncapped visa category, growing from 16,550 primary visa grants in 1997-98 to 40,720 by 2006-07 (Joint Standing Committee on Migration 2007), 68,480 in 2012-13, and dropping back to 51,130 in 2014-15 (DIBP 2015). Over its twenty year existence this program has inspired episodes of heated public debate-reflecting common criticisms of temporary labour migration programs found within international and theoretical debates. Such critiques have addressed negative impacts on the employment opportunities and conditions of local workers (Bissett and Landau 2008; Toh and Quinlan 2009) and the exploitation of migrant workers, which has been highlighted internationally particularly in relation to migrant workers in low skilled occupations (ILO 2004; HRW 2006). More recently, temporary migrant labour programs have been vigorously debated in several countries including the UK, Canada and Australia, where the concept of precarious migrant status has been invoked to highlight links between migration policy and workers' vulnerability as temporary residents in and beyond the labour market (Anderson 2010; Fudge and McPhail 2009; Goldring et al 2009; Boese et al 2013).

At the time it was established, the program's central purpose was to respond to labour market skills shortages and employer demand for workers by liberalising temporary entry rules. The program was initially designed to facilitate the entry of key business personnel such as senior executives or technical specialists, and was not intended to apply to traditional skilled trades or to professions like nursing and teaching. However, the program has been increasingly used to bring in trades people and semi-skilled workers in hospitality, mining, manufacturing and construction (Bissett and Landau 2008; Howe 2010).

The duration of the 457 visa varies from one day up to four years and several renewals are possible. Visa holders are entitled to bring members of the immediate family who also have a right to work. The program does not grant a right to transition to permanent residency.

However it provides the possibility of a pathway to permanent residence. Recent estimates suggest that the number of 457 visa holders becoming permanent residents is up to half the number of new 457 visas issued in any given year (Mares 2012). The right to bring family members along, who also have the right to work on the secondary visa, is another indication of the program being set up to operate both as a temporary program and a two-way trial period for both employers, and workers and their families. The visa has indeed been marketed to employers as a 'try before you buy' option. ${ }^{3}$

Successful application for a 457 visa requires workers to be sponsored by an approved employer. ${ }^{4}$ This gives employers significant control over the numbers and kinds of workers entering under the program. 457 visa-holders can transfer employer sponsors provided that

\footnotetext{
${ }^{3}$ See for example: Chamber of Commerce and Industry of Western Australia. https://cciwa.com/docs/default-source/migration-docs/2950 did-you-know-awareness-pdf final 1.pdf?sfvrsn ${ }^{4}$ This can occur in different forms with the most important being through individual business sponsorship and Labour Agreements (Tham and Campbell 2013). This paper only speaks to the case of temporary migration through individual business sponsorship.
} 
the new employer is also an approved employer. The transfer has to occur within a set timeframe, which used to be 28 days and was extended to three months in 2013. Failing to find an alternative employer, the visa holder is in breach of their visa conditions and liable to be removed from Australia. Moreover, the most popular pathway to permanent residency is via an employer-sponsored skilled visa, which exacerbates the temporary migrant's dependency on their employer (Deegan 2008).

The most vocal criticisms of the program in Australia have centred on the program's impacts on Australian labour market conditions (Bissett and Landau 2008), employers 'rorting' the program (O'Connor 2013), and the exploitation of workers by their employer sponsors or labour market intermediaries (Cullen and McSherry 2009; Velayutham 2013). ${ }^{5}$ Recent concerns have also been raised about the limited entitlement of 457 visa holders to a range of social security benefits (Mares 2013; Boucher and Carney 2014). For example, temporary migrant workers admitted under the 457 program are not eligible for Australia's Medicare system of publicly provided medical and hospital services, or the Pharmaceutical Benefits Scheme (PBS), which provides access to publicly subsidised prescription drugs (O'Brien and Phillips 2015). In some Australian states (such as New South Wales) migrant workers' children are required to pay additional fees to attend school. Moreover, with few exceptions migrants living in Australia on 457 visas have no access to the settlement support extended to other groups of new entrants, such as advice on accommodation upon arrival, or English classes for family members who have moved to Australia with the primary visa holder. In addition, neither primary visa holders nor their family members have access to employment services, unemployment benefits or most other categories of social security payments (Larsen 2013). It is widespread efforts to justify such restrictions with reference to migrant consent that constitutes the central object of our critical analysis in this paper.

\section{Method of critical evaluation}

Our goal is to critically evaluate the way in which relevant features of the program have been justified by many of the program's architects and advocates with reference to claims about migrant consent.

The first step in conducting such a critique is to present an explicit account of the assumptions that underpin such justifications for the existing provisions of the 457 visa program. The consent-based rationale for the program's provisions can be understood as built on claims or assumptions of three kinds, regarding:

1) The underlying values that a consent-based rationale seeks to protect, which as we will see are focused on the protection of individual autonomy and welfare;

2) The design and practical functioning of what we refer to as protective mechanisms - that is, institutions or processes that are intended to protect these underlying values - in this context, via measures designed to enable informed and substantively unconstrained choice; and

3) A set of - often implicit - assumptions about the underlying social conditions of individual choice that influence the practical capacity of protective mechanisms to support underlying values

\footnotetext{
${ }^{5}$ Numerous cases of abuse have been brought to light in the course of multiple enquiries into and reviews of the program, in particular submissions to the Joint Standing Committee on Migration's 2006-2007 inquiry; the 2007/2008 Deegan Review; the 2014 Integrity Review and the 2015 Senate Inquiry into skilled visas.
} 
To empirically document articulations of the consent-based justificatory argument in which we are interested, we examine relevant policy documents for both overt and indirect articulations of these assumptions and claims, expressed by architects or advocates of the program. Although such claims or assumptions are often implicit, they are sometimes articulated more openly during episodes of public debate or revision of the program. Such assumptions can also be located within wider scholarly debates on both migration and consent, which more indirectly shape the ideological and political environment in which the program is publicly justified.

Having conceptualised and empirically documented the central elements of the consent-based rationale on which our critique focuses, the next step is to empirically evaluate the validity of relevant assumptions and claims. In concrete terms, this entails empirical scrutiny of how protective mechanisms designed to facilitate informed consent work in practice, and of the extent to which such mechanisms are able to create institutional and social conditions in which migrants can make substantively unconstrained choices. To carry out this evaluation, we draw on evidence from our case study of the experiences of temporary migrant nurses.

The purpose of an internal critique of this kind is to speak to established normative commitments of many architects and supporters of the program. Accordingly, it differs from methods of immanent critique commonly used within a critical theory tradition, in that it does not claim to provide a basis for more radical or transformative modes of social critique and reform (Moan 2008). It differs from analytical modes of normative critique in that it does not seek to morally condemn the program from the perspective of external normative standards that do not resonate with the existing values and commitments of those engaged in the existing debate (Stahl 2013). Rather, the normative and political purpose of such a critique is to help political actors ensure that political agendas they promote or support are consistent with their own underlying political values and principled commitments (Macdonald and Macdonald 2010).

\section{Consent-based justifications of the 457 visa program}

Our first task is to present a more substantive interpretation and exposition of the key elements of consent-based justifications of the 457 visa program-drawing on the diverse sources of evidence identified above. We identify briefly in turn the program's underlying liberal values; the consent-based protective mechanisms it endorses and relies upon as means of protecting these values; and its underlying assumptions about the capacities of individual migrants to make rational, unconstrained and welfare-enhancing choices throughout their navigation of individual migration pathways.

Let us first consider the underlying liberal values. As we might expect, the normative values that underpin justifications of the program are rarely articulated in explicit form. Nonetheless, the principled foundation for key elements of Australia's 457 visa program can be clearly situated with reference to liberal values and ideologies. From its inception as a visa program that facilitated employers' access to temporary migrant labour, to later steps of liberalizing regulations in response to business demands for more flexible labour market policies (Wright 2015; Tham and Campbell 2013), the program has been underpinned by a market-oriented liberal ideology of business competitiveness. This orientation is then balanced-at times uneasily - with a parallel commitment to the protection of individual autonomy and welfare. These latter values are foundational to many currents of liberal thought, reflecting central concern for the intrinsic value of individual choice and autonomy. For many liberal thinkers, 
such values are also underpinned by a conviction that protections for individual liberty can in turn help protect and enhance individual welfare or utility (Corrigan 2003; Faden and Beauchamp 1986; Schuck 1994). Such liberal normative commitments are rarely articulated explicitly in these terms, though the value of protecting individual rights and choices receives consistent emphasis in justifications of the program, particularly as a basis for justifying reforms to the program. For example, the introduction of explicit English language requirements in 2007, and their later tightening, was justified in part as a means of protecting temporary migrants" "rights and their ability to stand up for these" (Department of Immigration and Citizenship (DIAC) 2007) — clearly invoking concerns about both the welfare and autonomy of temporary migrants.

A commitment to mechanisms of choice and consent as a basis for defending underlying liberal values possesses an almost foundational status within liberal political thought. (Shapiro and Wendt 1992) for example characterise a commitment to consent as "a linchpin of Western political consciousness" (p.197), and "the basic legitimating device of [liberal] moral arguments" (p.199). Consent is often viewed as particularly important as a basis for justifying the imposition on individuals of binding obligations, or acceptance by individuals of limits to individual rights (Robertson 2005; Brilmayer 1989). Ottonelli and Torresi suggest in the context of migration that a "focus on voluntariness is important because it looks at migration from the point of view of the migrants themselves and takes them into account as agents ... The recognition of human agency is a crucial element of liberal justice, which lies at the heart of liberal rights and institutions and of the equal concern and respect that they give to people" (Ottonelli and Torresi 2012, p.789).

Within economic migration theory and debates on labour migration policy, a focus on agency and choice has long been prominent. Classical and neoclassical economic analyses of migration decisions have portrayed migrants as rational actors who base their decisions on cost-benefit calculations in relation to labour market opportunities, wage differentials or the generosity of the welfare system in the destination country (Borjas 1989; Koopmans 2010; Chiswick 2000). Labour economist Michael Piore (1979) described temporary migrants in particular as 'probably the closest thing in real life to the homo economicus of economic theory' based on their 'purely instrumental' migration motives (Piore 1979, p.54). More recently, economists have emphasised the substantial material benefits of economic migration for individual migrants, their families and sending countries in receipt of remittances. Ruhs argues that many workers coming from low and middle income countries make rational choices to "seek better access to labor markets in higher-income countries" (Ruhs 2013, 125), suggesting that workers thereby signal their willingness "to tolerate, at least temporarily, a trade-off between better economic outcomes ... such as higher wages and family income, and fewer rights" (Ruhs 2013, 128). In a similar vein, Pritchett $(2006,86)$ challenges critiques of the differential treatment of migrant workers in Gulf countries by pointing to the "entirely voluntary choices" migrants make when they accept inferior rights to nationals in countries that offer them superior economic opportunities to those available in their home-countries.

Consent is rarely seen by liberals to be a sufficient condition for justifying a given set of institutional arrangements. For example, it is commonly acknowledged that individuals cannot legitimately consent to violations of inalienable rights (Peter 2004).

It is also often argued that individuals cannot legitimately consent to choices between options which can themselves be judged as unjust (with reference to some independent standard of justice) (Schuck 1994). Some political theorists interpret this requirement in a 
minimalist fashion, with reference to conditions of 'sufficiency', in which 'basic rights, variously understood, are protected" (Ottonelli and Torresi 2012, p.785). Others view such constraints on voluntary choice in a more expansive manner, whereby almost all migration choices are non-voluntary "because undertaken under non-ideal conditions determined by global injustices" (Ottonelli and Torresi 2012, pp.785-786). Despite recognition of such limits to the significance of consent, there remains a widespread view among liberals that institutional mechanisms designed to enable and protect individual consent play an important role in ensuring that the design of public institutions and policies remains consistent with underlying liberal values.

Reflecting these underlying liberal commitments, justification of the 457 visa program has rested importantly on broad assumptions about the capacity of individual migrant workers to consent to the prevailing terms of the program. Reflecting the program's initial focus on highly skilled workers, 457 visa holders have been represented as having unusually high capacity to make autonomous, rational choices that further their interests as participants in the program. For example, in 2012, former Australian Minister for Immigration and Citizenship Chris Bowen suggested that strong entry screening of applicants ensured that the recipients of these visas were "those people best equipped to succeed in the labour market and participate in Australian society", as well as being "less vulnerable to exploitation". Immigration Department representatives we interviewed for this research similarly characterised 457 visa holders as highly skilled and well-equipped to make rational, welfare-enhancing choices: "I think the first thing to recognize is most 457 visa holders are highly paid, have good English language ability and are highly skilled. So ... by and large I think most workers do not have the difficulty in making that transition".

\section{Evaluating practices of migrant consent}

Having laid out core assumptions underpinning consent-based justifications for restricted social entitlements of temporary migrant workers, we next consider what practical protective mechanisms are in place to enable and protect individual consent, under prevailing social conditions. As we explain, both theories and practices of individual choice and consent across a variety of contexts have converged on the view that choices must be meaningfully informed and substantively unconstrained, in order to enable outcomes that are both welfare-enhancing and supportive of individual autonomy (Katz 1977). We therefore evaluate the extent to which actual practices of choice by such migrants are sufficiently informed and substantively unconstrained to enable justification of the prevailing policy regime on the grounds that individual migrants have consented to it.

In analysing the empirical dynamics of migrant choices, our central focus is on the choices that temporary migrant nurses make with regard to their decision to apply for a 457 visa (whether onshore or offshore), and with regard to exit from status as a 457 holder. It is these decisions over which nurses would need to exercise free and informed choice in order to justify the prevailing terms of the visa program.

\section{Can temporary migrants make meaningfully informed choices?}

We first evaluate the practical operation of institutional mechanisms designed to ensure that migrants' choices about applying for a 457 visa can be meaningfully informed. To provide such protection, a basic requirement is that choices be made in the presence of adequate disclosure of relevant information. In deciding whether to apply for work in Australia under the 457 visa program, one important consideration for prospective migrant workers is clearly 
the economic opportunities and workplace conditions that they are likely to encounter. Also of importance is information about the broader social entitlements and responsibilities of temporary residency associated with the visa, and for many, the prospects of later attaining permanent residency. Moreover, individuals making migration choices must have the practical capacity to understand the implications of this information for resulting outcomes of relevant kinds (Robertson 2005) (Ottonelli and Torresi 2012, p.802).

The value of providing mechanisms designed to strengthen the capacity of individual migrants to make informed choices about their migration pathways has received sustained emphasis in both the design and ongoing reform and defence of the 457 visa program. Policy makers have placed particular emphasis on the importance of providing quality information to migrant workers with regard to the terms of employment contracts, and broader visa conditions and the prospects of permanent residency. A 2014 government report recommended that explicit articulation of "the rights and entitlements of 457 visa holders should always be included as part of the 457 visa holder's signed employment contract", and that such information should be more widely disseminated through "digital and social media channels" (Azarias et al. 2014, p.76) Similarly, a submission to the government's 2014 Integrity Review by Western Australia's Chamber of Commerce and Industry argued that:

If individuals were better informed when making choices to migrate for work purposes, mechanisms like the Temporary Skilled Migration Income Threshold [which was introduced to protect migrant workers from being underpaid] would not be needed ... CCI recommends that instead 457 visa holders be better informed on total costs when working and living in Australia, taking into consideration a lack of access to social services (CCIWA 2014).

What then does our empirical research suggest regarding the practical accessibility of such information for individual nurses seeking to make informed migration choices? Our interviews with migrant nurses highlighted significant limits to availability of such information for most migrants. Because migrant workers are often highly dependent on employers for provision of such information, levels of information varied to some extent depending on practices of individual employers.

Considering first information about economic opportunities and workplace conditions, nurses we interviewed identified a range of working conditions experienced in Australia that they felt they had been inadequately informed about prior to arriving. These included day to day issues applying to all workers, such as rostering practices, workloads or legally protected rights concerning wages and workplace conditions. They also included entitlements specific to 457 visa holders, such as employer obligations to pay for 457 visa holders' return air fares when they depart the country. Also highly valued by many nurses was information related to alternative employment opportunities and locations of work-particularly with regard to opportunities in regional or metropolitan areas. Some nurses reported having received misleading information from recruitment agents, based on the interest of these intermediaries in 'selling the position to the applicant', in the words of one migration agent. ${ }^{6}$ Information was also reported to be deficient with regard to the professional registration process in Australia. Given that nurses' ability to work is conditional upon their registration, the lack of

\footnotetext{
${ }^{6}$ Key informant interview, 24-04-12
} 
realistic information about prospective timeframes of the registration process was reported to be an important source of financial uncertainty faced by many visa applicants.

Reviews of the program have acknowledged the value of strengthening provision to visa applicants of such information regarding employment rights and opportunities. Information about broader living conditions and social entitlements under the 457 visa regime is even more relevant if a consent-based rationale is to justify exclusion of migrant workers from certain categories of social entitlements. Yet information provision on the costs of private health care, school fees or living costs has been even more limited in many cases.

Several interview participants revealed that they were surprised by the high living costs encountered in Australia, particularly the costs of accommodation. Those who had migrated with their children were faced with school fees and health care costs higher than they had anticipated. One nurse mentioned a colleague from India who had returned home to give birth because she could not afford the hospital costs in Australia. ${ }^{7}$ Some nurses had received information on living and healthcare costs from friends or their prospective employers, whilst others lacked access to such information and ended up doubting whether they would have made the same migration decision had they been better informed pre-departure. According to Mandy from the US: "[W]hen I got here I was surprised how expensive it was ... But I didn't have any great expectations I guess about living. ... I guess I knew I had to get health insurance but I didn't really know that much about it." ${ }^{8}$ With regard to health costs, one nurse from South Africa reported that she was aware of her obligation to buy private health insurance cover prior to arriving but lacked information on the extent of the expenses she would have to cover out of her own purse. ${ }^{9}$

For some nurses, recruitment agents played a critical role in controlling information flows. For example, Alex from the UK, who had been recruited at an overseas job fair, reported having been given the false impression that his accommodation would be organised for him in addition to other settlement assistance upon his arrival in Australia:

(T)hey said they are going to offer me accommodation and then they said secondly we are going to use sort of a tour - they'll be like a tour bus taking us around, showing us where like Melbourne to get to know places, just when you immigrate, and they'll help us settle down kind of thing. And then when we came over we didn't get anything like that, the only thing we did was an induction and then they said 'there you are you have to go to work' without any more than that. ${ }^{10}$

For workers whose migration decisions were influenced by a desire to transition to permanent resident status, the lack of comprehensive information about their prospects of achieving such a transition was a further constraint. Nurses who hoped to acquire permanent residency had often received information about the possibility of employer sponsorship for permanent residency either from a migration agent or the Immigration department website. In some

\footnotetext{
${ }^{7}$ The government permits insurers providing 457 health insurance to impose waiting periods of 12 months for pregnancy-related conditions alongside others. If a 457 visa holder falls pregnant in the first year of their residency, this means that they will have no coverage for admission to a hospital for child birth (see O'Brien and Phillips 2015, 560).

${ }^{8}$ Nurse interview 20047

${ }^{9}$ Nurse interview $2006 \overline{12} \_13$

${ }^{10}$ Nurse interview 300712_22
} 
cases, migration agents played an important role in providing misinformation that a specific employer would sponsor migrants in the future. In other cases employers themselves drew workers' attention to the possibility of their acting as sponsor for a permanent residence visa. $^{11}$

The perception amongst some migrants that time spent on the 457 visa functions as a kind of interim waiting period before attaining sponsorship for permanent residency influences the choices of some migrant workers to accept working conditions and restricted social rights that they might not otherwise be willing to tolerate (Deegan 2008; Mares 2014). Many migrant workers in our sample had made the choice to apply for the 457 visa not only on the basis of expecting certain employment opportunities and working conditions in the short term but also on the basis of expecting that this choice would lead to gaining permanent residency in Australia. For these workers, informed choice would require not only information about immediate employment opportunities and conditions, and attendant social entitlements and living conditions for themselves and their families, but also more reliable information with which to assess their likely future employment and residency prospects. Meera from India took her job in the belief that she would gain sponsorship for permanent residency:

I've been here in this hospital for almost one year but they haven't supported me for my permanent residency at all. ... when I joined there, they supported a few people but after that they stopped supporting for permanent residency, but I don't know the reason because all the employees all over Australia, even I have friends in Sydney and few friends in Perth now, and most of them ... got their permanent residency through their employer. ${ }^{12}$

A measure of uncertainty in migrants' decision making processes with regard to future events is of course inevitable. Many theoretical accounts of informed consent accommodate this by characterising the act of consent as entailing acceptance of some responsibility for unavoidable social risk (Robertson 2005). In this case, however, there are significant gaps in provision of relevant information that is available. It could be argued that it is the migrants' responsibility to source information on issues such as living costs or private healthcare costs themselves. However other types of 'information', such as information about the likelihood of being sponsored for permanent residency, is not freely accessible to prospective migrants since such prospects are dependent on the discretion of employers. Much of the uncertainty that temporary migrant workers experience thus does not result from the inherent contingency of uncontrollable or unpredictable future events. Rather, it results from the control of information by employers, labour market intermediaries such as recruitment or migration agents (who benefit commercially from migrants' information gaps and were identified by our research as frequent sources of misinformation), or government officials, on whom all migrant workers remain dependent in significant ways. Such power imbalances between actors with regard to access to information further challenge the value of autonomyprotection on which a consent-based rationale is grounded.

\section{Do temporary migrants make choices that are substantively unconstrained?}

The value of specific protective mechanisms to guard against migrant choices being coerced or otherwise substantively constrained has also been emphasised by liberal analyses of

\footnotetext{
${ }^{11}$ See also the report of the 2014 Independent Review of Integrity in the subclass 457 Program (Azarias Lambert et al 2014) and submissions to the Review (for example (Mares 2014).

12 Nurse interview 01032012_2
} 
consent across a variety of contexts. In the absence of direct physical or psychological coercion (Ottonelli and Torresi, p.796-797), it is often socio-economic forms of power or vulnerability that constrain individual choice in relevant ways (Shapiro and Wendt 1992; Robertson 2005). Such constraints are particularly salient in the migration context, where 'voluntary' choices of migrants often reflect a paucity of other acceptable livelihood options for marginalised individuals (Carens 2008). Prominent public reviews of the 457 visa program have acknowledged the constraints that such power imbalances place on the choices of migrant workers. Such constraints have been recognised as particularly prevalent among migrants from non-English speaking countries and who hold a strong desire for permanent residency - characteristics that have also been linked to greater vulnerability to exploitation once migrants are in Australia (Deegan 2008, p.54).

Emphasis has often also been placed on the capacity of workers to freely exit receiving countries if they discover after arrival that the conditions of the program are not what they expected. As Ottonelli and Torresi highlight, existence of a viable exit option requires not only the physical possibility of returning to one's original country, but also the sufficiency of means for creating a decent life back home, under conditions that may have changed considerably since the original decision to migrate was made (Ottonelli and Torresi 2012, pp.801-802). Existence of a viable exit option is often interpreted as an important basis for inferring 'tacit consent' to prevailing arrangements. Tacit consent has been distinguished from 'express' consent on the basis that it does not require any explicit signal of consent, but can be inferred from more passive forms of acceptance of a given state of affairs (Simmons 1976). On this view, where migrants choose to remain in the receiving country, to accept associated benefits and to follow associated social rules and conventions (Fried 2003), it can be inferred that migrants have tacitly consented to the prevailing terms of receiving country migration policy (Bell and Piper 2005).

We found no evidence to suggest that decisions of temporary migrant nurses to participate in the 457 visa program had been directly coerced. However, our research documented significant practical constraints on the capacity of migrant nurses to exercise their theoretically available 'exit option', through reversing their chosen migration pathways if conditions proved more adverse than they had anticipated.

Meera from India spoke to us about her dreaded alternative plan in case her employer failed to sponsor her permanent residency, highlighting that she did not even consider 'exit' understood as a permanent return to her origin country as an option.

It's only this particular employer where they're saying they're not supporting permanent residency at the moment. So that means when I finish my visa, I have to go back to India or I have to apply for my permanent residency by myself. I'm staying by myself - it takes almost 18 months and I have to do IELTS and it's lots of paperwork. For me, it is stressful now. ${ }^{13}$

The only 'exit' option this nurse considered was hence the pathway to permanent residency via an independent visa, which was more costly and a lengthier process.

Exit options are of course experienced very differently by those nurses that consider returning to their country of origin, as opposed to those who harbour hopes for achieving permanent

${ }^{13}$ Nurse interview 01032012_2 
residency status in Australia. For the former group - in our sample a minority of two nurses from the US - it might be the practical and financial difficulties associated with returning to life in another country that keep temporary migrants from exiting their situation as soon as their expectations are not fulfilled. This case was also illustrated by the experience of Claire, who was unable to work for a period following an injury but could not have returned to the UK easily either:

(Y)ou just really end up stuck, like a lot of people are like "Well are (you) going to go home?" but I couldn't go home because I didn't have any health insurance at home.

So I think maybe ... I don't know if there needs to be a little disclaimer, because that was something that ... nobody involved in my coming to Australia had thought of. ${ }^{14}$

For those nurses who wish to stay on and seek permanent residency status, exit options are more fundamentally constrained. Most nurses in our sample belonged to that group and had either already acquired a PR, applied for one, or were intending to apply for one soon (see Appendix 1). For these nurses, if they are to realise this primary goal of migration, they must stay on even in face of unanticipated adverse outcomes or conditions with regard to their employment or broader living conditions. Not only does the desire to seek permanent residency obstruct exit options from the country in an obvious way, it can also create sources of structural dependency on employers, given their central role in supporting permanent residency. Employers are well aware of the freedom to leave a job that migrant workers gain once they hold a PR, thus strengthening the latter's bargaining power.

The nurses in our sample were limited by a 457 visa condition that was subsequently modified, which required them to find another employer to sponsor them on the 457 visa within 28 days of leaving their first employer, otherwise their visa would be cancelled and they would have to leave Australia. ${ }^{15}$ Some nurses were unaware of their right to change employers and thought that leaving their employer would mean ending their legitimate residency in Australia. Others had few hopes of securing another sponsor or could not afford the risk of quitting their job and searching for another sponsor in such a short period of time. For many, the most significant obstacle to realizing their right to leave was the hope for sponsorship for a permanent residency, which was most likely to be realized through their current employer. Josephine, a married nurse with two children from South Africa, described her experience of uncertainty and vulnerability related to her insecure residency status, in combination with dependency on the employment relationship and an overall lack of support:

You are always worried that if you do something wrong they're going to kick you out of the country. You don't feel very secure. You're also not, when you are on a temporary visa you are not entitled to any benefits. I'm not saying everyone benefits the moment they arrive here, but there's no one you can turn to if you get into trouble. You are basically on your own and you've got to think of whom, that's what it falls down to. ${ }^{16}$

Such dependency on employers, combined with misinformation and associated financial and social insecurity, not only undermines the autonomy of worker choices, it can also undermine worker welfare through intensifying nurses' vulnerability to exploitation. As highlighted in

\footnotetext{
${ }^{14}$ Nurse interview 200612_14.

15 This period was extended to 90 days in the 2013 Changes to the Program (http://www.immi.gov.au/skilled/changes-457-program.htm).

${ }^{16}$ Nurse interview 160712_23
} 
an Integrity Review of the program by Commissioner Barbara Deegan in 2008, "subclass 457 visa holders ... are the only group of employees whose ability to remain in Australia is largely dependent upon their employment and to a large extent, their employer. It is for these reasons that visa holders are vulnerable and are open to exploitation" (Deegan 2008, p.69).

\section{Discussion and conclusions: responsibility, vulnerability and the limits of consent}

The consent-based rationale used to justify the restricted social entitlements extended to migrant workers under Australia's 457 visa regime is grounded on a liberal commitment to the intrinsic normative value of individual autonomy, choice and agency, and on a claim that institutional processes directed towards enabling individual 'consent' to the terms of the program can effectively protect individual autonomy and enable welfare-enhancing outcomes. Such assumptions have played an important role in justifying the exclusion of temporary migrant workers from certain rights held by citizens or permanent residents. In particular, prominent labour, development and migration economists have drawn on notions of 'choice' and 'voluntariness' and the relative improvements migration affords to many workers from poorer countries to argue for labour mobility alongside unequal treatment (Ruhs 2013 and Pritchett 2006).

However, as we have seen, assumptions about the well-informed and substantively unconstrained character of migrant choices on which this justification is based are challenged by empirical evidence concerning the material conditions of migrant choices. Our analysis first documented significant limits to the quality of information provided to prospective migrant workers by private recruitment agents or government officials about how provisions of the 457 visa are likely to influence their employment opportunities, living conditions and prospects for pursuing a pathway to permanent residency. We then examined constraints on the autonomy of migrants' choices in relation to their initial decisions to come to Australia under the visa program, and subsequent decisions to remain or leave. Most temporary migrant nurses we spoke with had access to alternative livelihood or migration options at the point of choosing to come to Australia under the 457 visa program, so they were exercising meaningful choice of some kind at the point of entry. Nonetheless, many experienced significant constraints to their exit options, resulting both from their vulnerable position as workers on a temporary visa, and in many cases also from additional dependencies related to their intended long-term migration pathways. Such constraints were particularly pronounced in cases where workers were from poorer countries and low socioeconomic backgrounds, experienced increasing financial pressures, or had limited English skills, decreasing their options in the Australian labour market and rendering them even more vulnerable to employer exploitation.

In part, limits to the informed and substantively unconstrained quality of migrant choices were shown to result from features of the 457 visa program's own design - particularly a tension between the nominal character of the program's facilitation of temporary residency, and the program's de facto function as a potential entry into permanent residency, or as one analyst of temporary skilled migration programs put it, "a first sieve for selecting those who can be successfully integrated as permanent migrants" (Abella 2006, p.23). Whilst this function is only unofficially acknowledged in Australia, in practice it influences migrants' decision making processes in significant ways - allowing entire families to uproot themselves and settle in Australia for several years with a prospect, albeit no guarantee, of permanent residency. Similar to some skilled temporary labour migration schemes in other high income countries such as the US and Canada, the Australian program is particularly attractive to 
migrants with long-term settlement aspirations, not only because of the permanent residency pathway, but also because its design grants the family members of 457 visa holders the right to work. Paradoxically, although these features of the Australian program in some respects enhance the rights of migrants, on the other hand the potential for-as opposed to a right totransition to permanent residency through employer sponsorship often intensifies dependencies of migrant workers on their employers.

In part, the vulnerabilities that migrants experience with regard to accessing meaningful information and the availability of exit options result from their subordinate position within societal power relations that extend well beyond the narrow parameters of the visa program. Migrants' choices are shaped amongst other factors by a macro context of intense global inequalities and a micro context of asymmetrical power relationships in the workplace. Choices that individuals make thus never occur within social relations that are free from power or perfectly fair. As Berg has highlighted, vesting individuals "with total responsibility for the costs of their action ... fails to recognize that 'choices' are inevitably structured by social context, including social expectations, and that decisions often carry unanticipated consequences" (Berg 2015, 42). To what point then can liberal theory justify holding individuals responsible for adverse consequences of their own choices, as liberal, consentbased justifications for restricted social entitlements for migrants seek to do?

First, most liberals recognise the need for substantive autonomy of some kind as a condition for authoritative forms of consent - though they disagree on appropriate thresholds of autonomy or empowerment. ${ }^{17}$ Such a view implies that individuals could be held responsible for their restricted social entitlements only to the extent that their choices were sufficiently autonomous or empowered in the relevant sense. Relevant sources of autonomy or empowerment in this context include not only the capacities of individual migrants, but also external sources of dependency and vulnerability they experience as a result of their position within wider policy and labour market regimes. As we have argued, relevant forms of dependency and vulnerability are often significant. With reference to the 457 visa program, we have seen that it is clearly not a 'try before you buy' option for temporary migrants in the same way as it is for their employers, as only the latter are empowered to determine if they will support a migrant's transition from temporary to permanent residency via sponsorship. Moreover, workers remain vulnerable to exploitation within their asymmetrical power relationships with employers - a power imbalance that has often been intensified by liberalized labour market regimes. Somewhat paradoxically, labour market and economic policies associated with broader liberal regimes are thus contributing to undermining liberal, consent-based justifications for the 457 visa regime, by eroding the background conditions for autonomous individual choice on the part of structurally vulnerable individuals.

Some defenders of the current arrangements could contend in response that while such arguments may hold sway in an ideal world, in the non-ideal world we live in, lower thresholds of empowerment and autonomy need realistically to be accepted. In this regard, it is salient to consider another layer of liberal argument which relates to the responsibility of political institutions. On this view, one of the ways that liberals can reconcile inevitable power imbalances and vulnerabilities in social life with a commitment to individual choice is to assign political institutions responsibility for actively countering such vulnerabilitiesdeploying their authority to help level the playing field in the social domain to an extent

\footnotetext{
${ }^{17}$ A fuller account of what autonomous choice requires is beyond the scope of the present discussion, but see for example Christman (1991).
} 
sufficient to maintain substantive autonomy of individuals within reasonable thresholds. From this perspective, what is particularly objectionable about the restricted social entitlements under the 457 regime is that the visa program not only fails to bolster the position of migrant workers who may already be experiencing structural vulnerabilities as a result of their position as temporary residents often originating from poorer countries; it further compounds their vulnerabilities to exploitation, by weakening their financial position and intensifying dependence on employers and private intermediaries. It therefore cannot be said that choices of migrants to trade-off short term rights for long-term economic gains are the best possible choices available to them in an imperfect world. Rather, vulnerabilities are being enabled and in some cases actively compounded as a result of the government's policy regime.

Our analysis therefore leads to the conclusion that the liberal aims and justifications of the 457 visa program are not currently being pursued in a way that safeguards the underlying liberal values that the program's architects and supporters are committed to protecting. Stephen Castles $(2015,2)$ has recently argued in a historical review of inequality in capitalist labour markets that the differential treatment of migrant workers and 'the ideologies used to legitimate [such practices]... go against a central principle of liberal capitalism: namely the principle of freedom, which means that all individuals may seek to maximize their benefits and that as market participants they should have equal rights and opportunities. Such equality has never been achieved in practice.' In the specific context of temporary migrant workers, we have shown similarly that the complex social, political and policy environment in which individual migrant choice occurs operates in practice to weaken the autonomy and control that individual migrants hold over important conditions of their lives, and undermine assumptions about the welfare-enhancing consequences of voluntary migration choices that have been used to justify the denial of social entitlements to migrant workers. Against background social conditions of significant migrant vulnerability, pushing responsibility for associated risks onto structurally vulnerable individuals through logics of consent cannot be justified.

\section{References}

Abella, Manolo. 2006. "Policies and Best Practices for Management of Temporary MIgration." In International Symposium on International Migration and Development, edited by United Nations Secretariat Department of Economic and Social Affairs. UN/POP/MIG/SYMP/2006/03.

Anderson, Bridget. 2010. "Migration, immigration controls and the fashioning of precarious workers." Work, Employment and Society 24(2): 300-317.

Agunias, Dovelyn , and Kathleen Newland. 2007. "Circular Migration and Development: Trends, Policy Routes and Ways Forward." Policy Brief. Washington, D.C.: Migration Policy Institute.

Azarias, J., J. Lambert, P. McDonald, and K. Malyon. 2014. "Robust New Foundations. A Streamlined, Transparent and Responsive System for the 457 Programme. An Independent Review into Integrity in the Subclass 457 Programme." Canberra: Department of Immigration and Border Protection.

Bell, Daniel, and Nicola Piper. 2005. "Justice for migrant workers? The case of foreign domestic workers in Hong Kong and Singapore." Multiculturalism in Asia 196-222.

Berg, Laurie. 2015. Migrant Rights at Work: Law's precariousness at the intersection of immigration and labour. London: Taylor and Francis. 
Bissett, Michelle, and Ingrid Landau. 2008. "Australia's 457 visa scheme and the rights of migrant workers." Alternative Law Journal 33 (3):142-6.

Boese, Martina, Iain Campbell, Winsome Roberts, and Joo-Cheong Tham. 2013. "Temporary migrant nurses in Australia: Sites and sources of precariousness." Employment and Labour Relations Review 24 (3):316-39

Borjas, George J. 1989. "Economic theory and international migration." International Migration Review 23 (3):457-85.

Boucher, Anna and and Terry Carney. 2014. "Social Security for Migrant Workers and their Families in Australia." In Social Security and Migrant Workers: Selected Studies of Cross-Border Social Security Mechanisms, edited by R. Blanpain, 187-214. The Netherlands: Kluwer Law international

Brilmayer, Lea. 1989. "Consent, Contract and Territory." In Faculty Scholarship Series. Yale University.

Carens, Joseph H. 2008. "Live-in Domestics, Seasonal Workers, and Others Hard to Locate on the Map of Democracy." Journal of Political Philosophy 16 (4).

Castles, Stephen. 2015. "Migration, Precarious Work, and Rights." In Migration, Precarity, and Global Governance: Challenges and Opportunities for Labour. edited by C.-U. Schierup, R. Munck, B. Likic-Brboric and A. Neergaard. Oxford Scholarship Online.

CCIWA. 2014. "Submission to the Independent Review of Integrity in the subclass 457 programme." Chamber of Commerce and Industry of Western Australia.

Chiswick, B.R. . 2000. "Are migrants favourably self-selected? An economic analysis." In Migration theory: Talking across disciplines, , edited by C.B.Bretell and J.F.Hollifield, 61-7. London: Routledge.

Christman, John. "Liberalism and individual positive freedom." Ethics 101.2 (1991): 343-359

Commonwealth. 2012. "Migration Legislation Amendment Regulation 2012 (No 4) " In F2012L0204, Commonwealth Government of Australia.

Corrigan, Oonagh. 2003. "Empty Ethics: The problem with informed consent." Sociology of Health and Illness 25 (3):768-92.

Cullen, Miriam, and Bernadette M McSherry. 2009. "Without Sex: Slavery, Trafficking in Persons and the Exploitation of Labour in Australia." Alternative Law Journal 34 (1):4.

Deegan, Barbara. 2008. "Visa Subclass 457 Integrity Review." Final report. Commonwealth of Australia.

Department of Immigration and Border Protection (DIBP). 2015. "Annual Report 2014-15." Commonwealth Government of Australia.

Department of Immigration and Citizenship (DIAC). 2007. "Submission to the Inquiry of the Joint Standing Committee on Migration into eligibility requirements and monitoring, enforcement and reporting arrangements for temporary business visas, submission No 33." Commonwealth Government.

Faden, Ruth, and Tom Beauchamp. 1986. A History and Theory of Informed Consent.

Fried, Barbara H. 2003. "'If You Don't Like It, Leave It": The Problem of Exit in Social Contractarian Arguments." Philosophy \& public affairs 31 (1):40-70.

Fudge, Judy. and MacPhail, Fiona. 2009. "The Temporary Foreign Worker Program in Canada: Low-skilled workers as an extreme form of flexible labour." Comparative Labour Law and Policy Journal 31(1): 101-141.

Global Commission on International Migration. GCIM. 2005. "Migration in an Interconnected World: New Directions for Action: Report of the Global Commission on International Migration." Geneva: Global Commission on International Migration.

Howe, J. 2010. "The Migration Legislation Amendment (Worker Protection) Act 2008." Alternative Law Journal 23:251. 
Human Rights Watch (HRW). 2006. Building Towers, Cheating Workers. Exploitation of Migrant Construction Workers in the United Arab Emirates. Available online at https://www.hrw.org/report/2006/11/11/building-towers-cheatingworkers/exploitation-migrant-construction-workers-united (last accessed 15 July 2016).

International Labour Office. ILO.2004. Towards a fair deal for migrant workers in the global economy. Geneva: ILO.

Joint Standing Committee on Migration. 2007. "Temporary visas ... permanent benefits. Ensuring the effectiveness, fairness and integrity of the temporary business visa program." Commonwealth of Australia.

Katz, Jay. 1977. "Informed Consent - A Fairy Tale? Law's Vision." University of Pittsburgh Law Review 39 (2).

Koopmans, Ruud. 2010. "Trade-Offs between Equality and Difference: Immigrant Integration, Multiculturalism and the Welfare State in Cross-National Perspective." Journal of Ethnic and Migration Studies 36 (1):1-16.

Larsen, Gareth. 2013. "The subclass 457 visa: a quick guide." Parliamentary Library Research papers.

Lenard, Patti Tamara, and Christine Straehle. 2010. "Temporary labour migration: Exploitation, tool of development, or both?" Policy and Society 29 (4):283-94. doi: 10.1016/j.polsoc.2010.09.006.

Macdonald, Kate, and Terry Macdonald. 2010. "The liberal battlefields of global business regulation." Ethics and Global Politics 3 (4):303-24.

Mares, Peter. 2012. "Temporary Migration and its Implications for Australia." Parliament of Australia. Canberra: Parliament of Australia. . 2013. "Falling between the cracks of temporary migration." In Inside Story. 1 November 2013.

— 2014. "Submission to the Independent Review of Integrity in the Subclass 457 Programme." Swinburne University of Technology.

Martin, Philip, and Martin Ruhs. 2008. "Numbers versus rights: Trade-offs and Guestworker Programs." International Migration Review 42 (1):249-65.

McKenzie, Nick, and Ben Schneiders. 2013. "Visa scheme rorting leaves foreigners in debt bondage." In The Age. 16 June 2013.

Moan, Marit Hovdal. 2008. "Immigration Policy and "Immanent Critique"." Ethics \& International Affairs 22 (2):205-11.

O'Brien, Paula, and Melissa Phillips. 2015. "Healthcare justice for temporary migrant workers on 457 visas in Australia: A case study of internationally qualified nurses." Journal of Law and Medicine 22 (March):550-67.

O'Connor, Brendan 2013. "Reforms needed to curb 457 rise." Minister for Immigration Multicultural Affairs and Citizenship. Media release 4 April 2013.

Ottonelli, Valeria, and Tiziana Torresi. 2012. "Inclusivist Egalitarian Liberalism and Temporary Migration: A Dilemma." The Journal of Political Philosophy 20 (2):20224.

Peter, Fabienne. 2004. "Choice, consent, and the legitimacy of market transactions." Economics and Philosophy 20 (01):1-18.

Piore, Michael. 1979. Birds of Passage: Migrant labor in industrial societies. Cambridge: Cambridge University Press.

Pritchett, Lant. 2006. "Let their people come." Center for Global Development, Washington. Robertson, Andrew. 2005. "The Limits of Voluntariness in Contract." Melbourne University Law Review 29:179-217.

Ruhs, Martin. 2013. The Price of Rights. Princeton: Princeton University Press. 
Schuck, Peter. 1994. "Rethinking Informed Consent." In.: Faculty Scholarship Series, Yale Law School

Shapiro, and Wendt. 1992. "The Difference that Realism Makes: Social Science and the Politics of Consent." Politics \& Society 20.

Simmons, A John. 1976. "Tacit consent and political obligation." Philosophy \& public affairs:274-91.

Stahl, Titus. 2013. "What is Immanent Critique?" In SSRN Working Papers. URL: http://ssrn.com/abstract=2357957, doi: 10.2139/ssrn.2357957.

Stilz, Anna. 2010. "Guestworkers and second-class citizenship." Policy and Society 29 (4):295-307. doi: 10.1016/j.polsoc.2010.09.005.

Tham, Joo Cheong, and Iain Campbell. 2013. "Labour market deregulation and temporary migrant labour schemes: An analysis of the 457 visa program." Australian Journal of Labour Law 26 (3):239-72.

Toh, Stefanie and Quinlan, Michael 2009. "Safeguarding the global contingent workforce? Guestworkers in Australia." International Journal of Manpower 30(5): 453-471.

Velayutham, Selvaraj. 2013. "Precarious Experiences of Indians in Australia on 457 Temporary Work Visas." Economic and Labour Relations Review 24 (3) 340-36

Walzer, Michael. 1983. Spheres of justice: A defense of pluralism and equality. Basic Books. Wellman, Christopher H. 2009. "Immigration and freedom of association." Ethics 119:10941.

Wright, Chris F. 2015. "Why Do States Adopt Liberal Immigration Policies? The Policymaking Dynamics of Skilled Visa Reform in Australia." Journal of Ethnic and Migration Studies 41(2): 306-328.

Yuan, Sylvia, Trudie Cain and Paul Spoonley. 2014. "Temporary Migrants as Vulnerable Workers: A Literature Review." Wellington, Ministry of Business, Innovation and Employment. 